\title{
Muscarinic Versus Nicotinic Modulation of a Visual Task: A PET Study Using Drug Probes
}

\author{
Marc J. Mentis, M.D., Trey Sunderland, M.D., Jennifer Lai, B.S., Catherine Connolly, M.D., \\ Jack Krasuski, M.D., Barbara Levine, M.D., Judy Friz, M.A., Sandeep Sobti, M.D., \\ Mark Schapiro, M.D., and Stanley I. Rapoport, M.D.
}

\begin{abstract}
Little is known about acetylcholine (ACh) modulation of central visual processing in humans. Receptor densities in visual brain regions are differentially distributed suggesting that receptor subtypes have different functions. Using PET, we have previously described the brain regions activated by a simple pattern-flash stimulus in healthy elderly subjects. To evaluate muscarinic and nicotinic contributions to ACh modulation of visual processing, we scanned elderly subjects watching the pattern-flash stimulus during no drug, during physostigmine augmentation, and during scopolamine antagonism of physostigmine's action. These manipulations of ACh significantly altered regional cerebral blood flow $(r C B F)$ in brain regions activated by the task. The pattern of $r C B F$ values across drug conditions suggested that
\end{abstract}

muscarinic and nicotinic effects were dissociated. Muscarinic action predominated in striate cortex (Brodmann Area, BA 17) and lateral visual association areas $(B A 18,19)$, while nicotinic action predominated in the thalamus and inferior parietal regions (BA 39/40). Both muscarinic and nicotinic actions increased $r C B F$ in some regions while decreasing it in others. A parsimonious reconciliation of these results with functional anatomy suggests that muscarinic action modulates visual attribute processing, while nicotinic action modulates arousal and selective attention to the visual task.

[Neuropsychopharmacology 25:555-564, 2001] (C) 2001 American College of Neuropsychopharmacology. Published by Elsevier Science Inc.
KEY WORDS: PET scan; Visual cortex; Photic stimulation; Regional blood flow; Acetylcholine; Anticholinesterase; Muscarinic blocker; Physostigmine; Scopolamine; Brain; Oxygen isotopes; Human

There is evidence that acetylcholine (ACh) is an important modulator of visual processing in vertebrates (Sillito and Kemp 1983; McCormick and Prince 1985; Sato et al. 1987a; London et al. 1988; Muller and

From the Laboratory of Neurosciences, NIA/NIH, Bethesda, MD (MJM, JK, BL, SS, MS, SIR), and Geriatric Psychiatric Branch, NIMH/NIH, Bethesda, MD (TS, JL, CC, JF).

Address correspondence to: Marc J Mentis, M.D., Center for Neuroscience, Boas Marks Research Center, North Shore University Hospital, 350 Community Drive, Manhasset, New York. 11030 U.S.A., Tel.: 516-562-1033, Fax: 516-562-1008, e-mail: marcjm@optonline.net

Received Jun 22, 2000; revised March 29, 2001; accepted April 3, 2001.

Online publication: 4/14/01 at www.acnp.org/citations/ Npp040401100.
Singer 1989; Barefoot et al. 2000). In humans, several studies have suggested that cholinergic modulation occurs within visual brain regions (Grasby et al. 1995; Bahro et al. 1999; Rosier et al. 1999). However, the relative contribution of muscarinic and nicotinic action to cholinergic modulation of visual processing on a regionby-region basis remains unknown. Such information would be useful for targeting cholinergic therapy in neurodegenerative disorders, especially those involving dysfunction in visual and visuo-associative systems.

Visual processing is hierarchical within distributed networks in monkeys (Livingstone and Hubel 1987; Desimone and Ungerleider 1989; Felleman and Van Essen 1991) and in man (Grady et al. 1990). After synapsing in lateral geniculate nucleus, visual impulses from the retina pass back to striate cortex where simple visual attributes are processed. More complex attributes are processed in progressively distal visual areas from 
occipital through parietal and temporal to frontal cortices (hierarchical). A rich cortical-subcortical loop is present between parieto-occipito-temporal association areas and the pulvinar region of the thalamus. Positional attributes of vision are processed in the dorsal occipito-parietal cortex, while form attributes are processed in the ventral occipito-temporal cortex. These two information streams constitute the two major distributed systems.

Ascending cholinergic pathways may serve an important role in modulating visual information processing. The anatomy of the cholinergic system in humans is complex, and is organized such that brain regions/ functions can be differentially modulated. Subcortical clusters of cholinergic nuclei in the basal forebrain (Ch1-4) and brainstem (Ch5-6) project topographically throughout the brain (for references see reviews: Fibiger and Vincent 1987; Geula and Mesulam 1994). Thus, Ch5 can influence pre-cortical (lateral geniculate nucleus) and cortical (via pulvinar) visual processing, whereas Ch4am and Ch4id subnuclei by projecting to lateral and medial parieto-occipital areas respectively, can have different effects on cortical visual processing. Further, cholinergic receptors are divided into five subtypes of muscarinic receptor (Kubo et al. 1986) and many subtypes of nicotinic receptor (Lukas et al. 1999). While autoradiographic, in situ hybridization and immunocytochemistry methods all identify abundant muscarinic and nicotinic receptors in brain regions responsible for visual processing, topographic detail of receptor density and position differs somewhat among the methods (for references see reviews: Clarke 1993; Court and Perry 1995; Martinez-Murillo and Rodrigo 1995; Robner and Schliebs 1995). A consistent finding, however, is that receptor density in visual brain regions and in brain layers within regions, the synaptic position of receptors, and the nature of receptor target neurons varies greatly among cholinergic receptor subtypes. As these characteristics are indicators of receptor function, it is likely that cholinergic receptor subtypes have different roles in modulating visual processing in man. An observation important for this study is that muscarinic receptors, particularly type 1 , have high densities in cortical visual regions, whereas nicotinic receptors have high densities in subcortical visual areas.

The idea of differential cholinergic modulation has been studied, primarily in animals, by manipulating ACh with drugs or lesions and recording the effects on brain function in various ways. Nicotinic action enhanced cerebral glucose utilization in subcortical brain regions associated with visual processing in a drug autoradiographic study of rats (London et al. 1988). In contrast, muscarinic action had differential effects on neural function in the striate cortex of cats during optic stimulation in single unit studies using iontophoretic application of drugs (Sillito and Kemp 1983; McCor- mick and Prince 1985; Sillito et al. 1985; Sato et al. 1987a,b; Muller and Singer 1989). These studies also demonstrated that iontophoretic application of ACh onto exposed brain changed firing rates of cortical visual neurons only during optic nerve stimulation, while no modulation of neuronal firing occurred in the absence of visual stimulation. This is an important characteristic of $\mathrm{ACh}$; it can function as a neuromodulator rather than as a primary neurotransmitter. This concept is supported by Barefoot et al. (Barefoot et al. 2000) who in a series of experiments involving various combinations of basal forebrain and inferior temporal lobe lesions in monkeys, concluded that the impaired visual discrimination caused by cholinergic insult resulted from withdrawal of cholinergic support for visual processing performed by the target cortical area.

In previous $\mathrm{H}_{2}{ }^{15} \mathrm{O}$ PET studies in humans, we have characterized changes in brain function associated with a simple pattern-flash stimulus from striate through frontal cortex (Mentis et al. 1996a; Mentis et al. 1997; Mentis et al. 1998). In the present study, we extended these findings by evaluating how pharmacological manipulation of $\mathrm{ACh}$ modulated function in these brain regions. We recorded the $\mathrm{rCBF}$ response to patternflash stimulation under three conditions: (1) without drug, (2) during augmentation of muscarinic and nicotinic function by the anticholinesterase physostigmine, (3) during muscarinic antagonism of physostigmine's action by scopolamine. The pattern of blood flow values across the three drug levels was used to determine whether ACh modulation of visual processing had a significant muscarinic and/or nicotinic component on a region-by-region basis.

\section{MATERIALS AND METHODS}

\section{Subjects}

Written consent was obtained in nineteen healthy subjects ( 7 males and 12 females, mean age 64 years \pm 9 SD) who agreed to participate in a protocol to evaluate $\mathrm{rCBF}$ changes with Positron Emission Tomography (PET) during visual stimulation with and without physostigmine and scopolamine. All nineteen subjects had NO-DRUG and PHYSO (physostigmine plus glycopyrrolate) PET scans. In addition, ten of these subjects (4 males and 6 females, mean age 60 years $\pm 9 \mathrm{SD}$ ) had a PHYSO+SCOP (physostigmine plus scopolamine) PET scan.

No subject had a significant medical disorder, as determined by history, physical examination, chest X-ray, EKG, magnetic resonance imaging, and laboratory tests (complete blood count, sedimentation rate, electrolytes, glucose, blood urea nitrogen, creatinine, liver-associated enzymes, cholesterol, triglycerides, antinuclear antibodies, VDRL, HIV, serum B12, folate, thyroid function and urinalysis). No subject had a visual abnormality as as- 
sessed by history and examination (opthalmoscopy, pupillary function, extraocular movement, acuity charts, and field integrity determined by confrontation response), asthma, acute-angle glaucoma or prostatic hypertrophy.

\section{Pattern-Flash Stimulus}

During each scan, a flashing stimulus was administered alternately to each eye at a single frequency by a pair of goggles (model S10VS B, Grass Instrument Co., Quincy, MA.) taped to a thermoplastic facemask. One of five frequencies $(0,1,4,7$, or $14 \mathrm{~Hz})$ was administered during each scan. Stimulus characteristics, $\mathrm{rCBF}$ responses, and subjective percepts in healthy subjects have been presented in detail (Mentis et al. 1997). Briefly, goggles that contained a 6 by 5 rectilinear grid $(1.52 \mathrm{~cm}$ by $1.27 \mathrm{~cm})$ delivered a stimulus from 30 monochromatic red light-emitting diodes (LED), mean peak $655 \mathrm{~nm}$, imbedded into each eyepiece. The grids subtended an arc of illumination of about $50^{\circ}$, were flashed alternately into left and right eyes, and the number of flashes presented to one eye per second was taken as the flash-frequency in Hz. Flash-frequency was varied by changing the duration of the interval between flashes. Flash duration was fixed at $5 \mathrm{msec}$. Luminous intensity of each flash remained constant at $3.6 \mathrm{mcd}$; therefore, as flash frequency increased so did luminous intensity per unit time.

\section{PET Scans}

A positron emission tomograph (model PC2048-15B, Scanditronix, Uppsala, Sweden) that has reconstructed transverse and axial resolutions of $6.5 \mathrm{~mm}$, was used to measure rCBF using $\mathrm{H}_{2}{ }^{15} \mathrm{O}$. To correct for photon attenuation by skull and cerebral tissue, a transmission scan was obtained during rotation of a ${ }^{68}$ germanium $/{ }^{68}$ gallium source around the subject's head. Head movement was minimized during and between scans with a thermoplastic mask molded to each subject's head and attached to the scanner bed. Thirty $\mathrm{mCi} \mathrm{H}_{2}{ }^{15} \mathrm{O}$ was injected intravenously as a bolus, and during the next four minutes data were collected simultaneously in 15 planes spaced $6.5 \mathrm{~mm}$ apart and parallel to the inferior orbital-meatal line. Sixteen images were obtained, twelve 10-second images followed by four 30-second images. Automatic arterial blood sampling with an indwelling catheter was initiated at the time of injection and was continued throughout the scanning period. Data from the $16 \mathrm{im}$ ages and the arterial time-activity curve were used to reconstruct the set of 15 slices composing each scan. rCBF was calculated using a rapid least squares method (Holden et al. 1981; Carson et al. 1987).

All subjects had arterial lines inserted for absolute quantification of CBF. Three scan sessions, NO-DRUG, $\mathrm{PHYSO}$, and PHYSO+SCOP, were performed on a sin- gle day. During the first scan session (5 scans), no drug was administered (NO-DRUG), and for the duration of each scan within the session the subject kept his/her eyes open and watched the pattern-flash stimulus at one of five frequencies $(0,1,4,7$ or $14 \mathrm{~Hz})$. Over the five scans within a session each frequency was presented once. The presentation of pattern-flash frequency was randomized and counterbalanced across subjects. During the second scan session (5 scans), physostigmine and glycopyrrolate were infused (PHYSO), and the same five pattern-flash frequencies were presented but in a different randomized order from the first scan session. The order was counterbalanced across patients. During the third scan session (3 scans), scopolamine and physostigmine were infused (PHYSO $+\mathrm{SCOP})$, and the subject watched one of 0,7 , or $14 \mathrm{~Hz}$ flash frequencies during each scan. A Buschke selective reminding task (Buschke and Fuld 1974) was performed before scopolamine administration (baseline value) and was repeated after completion of the third PHYSO+SCOP scan, to document the effect of PHYSO+SCOP on memory performance at the time of PET.

\section{Drug Administration}

Scopolamine Dose-finding Day. On the dose-finding day the administration of physostigmine, glycopyrrolate, and Buschke selective reminding tests was identical to that on the PET scan day (see below). The starting dose for scopolamine was $0.5 \mathrm{mg}$ infused intravenously over 1 minute. If $0.5 \mathrm{mg}$ scopolamine failed to reduce the Buschke score by greater than $25 \%$, the scopolamine dose-finding day was repeated every three days while increasing the scopolamine doses each day until the desired memory impairment was reached, or drug side effects halted the study. Only two subjects required more than $0.5 \mathrm{mg}$ and none received more than $0.75 \mathrm{mg}$.

Scan Day. After completion of the NO-DRUG PET scan session, $0.2 \mathrm{mg}$ glycopyrrolate, an antimuscarinic agent that does not cross the blood-brain-barrier, was given intravenously over one minute to prevent peripheral physostigmine side-effects. Then a physostigmine loading infusion of $1.93 \mathrm{mg} / \mathrm{hr}$ intravenously was given for 10 minutes, followed by a maintenance physostigmine intravenous infusion of $0.816 \mathrm{mg} / \mathrm{hr}$. The five PHYSO scans were performed during the maintenance physostigmine infusion. The maintenance infusion was stopped after completion of the fifth PHYSO scan. The physostigmine infusion and maintenance rates were calculated using pharmacokinetic data generated on patients in our laboratory. There was a 2 to 4 hour break between the second and third scan sessions to allow for glycopyrrolate metabolism, so that peripheral anti-muscarinic side-effects from subsequent scopolamine infusion in scan session 3 might be minimized. 
Before starting the PHYSO+SCOP scan session, a baseline Buschke selective reminding task was performed. Then an individually determined dose of scopolamine (see above) was given intravenously over one minute. Immediately thereafter, the same physostigmine loading and maintenance regimen as given in the PHYSO scan session was administered. The first PHYSO+SCOP scan was started 30 minutes after the scopolamine infusion, to allow for central muscarinic blockade, and the physostigmine maintenance was terminated in a stepwise fashion after the third PHYSO+SCOP scan. Immediately after completion of the third PHYSO+SCOP scan, the second Buschke selective reminding task was administered.

Drug Order Effects. We controlled for pattern-flash order effects by randomizing and counterbalancing the order of stimulus presentation. However, for safety reasons, we did not control for the order of presentation of the three drug conditions: no-drug first, physo second, and scop+physo third. Arterial lines were essential to evaluate any drug-induced absolute global CBF change that, if present, would have had profound statistical implications. All scan sessions needed to be on the same day, as we were not prepared to insert multiple arterial lines for this study. Further, the long duration of scopolamine effects required that it be administered last, and administering PHYSO before NO-DRUG would have required a between PET-session delay resulting in an unacceptably long total scan time. The third scan session (PHYSO+SCOP) consisted of only three of the five conditions $(0,7,14 \mathrm{~Hz})$ to avoid exceeding radiation safety limits. During all scan sessions subjects had continuous pulse, blood pressure, EKG and pO2 monitoring.

\section{Data Analysis}

Data Transformation Prior to Statistical Analysis. There was no difference in mean absolute CBF among the NO-DRUG, PHYSO, or PHYSO+SCOP conditions. That is, we observed no direct vascular effect of drug sufficient to result in a significant mean CBF difference between drug conditions. Global CBF for each scan was the mean rCBF value across a cumulative brainmask of voxels that included most gray and white matter from $-20 \mathrm{~mm}$ through $+56 \mathrm{~mm}$ relative to the anterior-posterior commissure line. Individual brain-masks were generated by finding those voxels with rCBF values $>33 \%$ of the maximal rCBF value for the scan. The cumulative brain-mask consisted of only those voxels present in all individual brain-masks. To reduce effects of differences in global CBF between subjects and within-subject between conditions, $\mathrm{rCBF}$ at each voxel was normalized to whole-brain $\mathrm{CBF}$ (rCBF at each voxel was divided by the global $\mathrm{CBF}$ of the scan from which it was derived); results were then multiplied by the mean of all scan CBF values across all subjects and all drug conditions. This procedure provided standardized values of $\mathrm{rCBF}$ in units $\mathrm{ml} / 100 \mathrm{~g} / \mathrm{min}$ (Mentis et al. 1996a,b). Images were registered, stereotaxically normalized into a standardized space (Talairach and Tournoux 1988), and smoothed by $15 \mathrm{~mm}$ by $15 \mathrm{~mm}$ by $10 \mathrm{~mm}$ in the $\mathrm{X}, \mathrm{Y}$, and $\mathrm{Z}$ axes $(\mathrm{X}=$ left $/$ right, $\mathrm{Y}=$ posterior/anterior, and $Z=$ inferior/superior) using Automated Image Registration (AIR) (Woods et al. 1998).

Statistical Analysis. Repeated measures Analyses of Variance (ANOVA) comparisons were performed on each brain voxel with a $C$ language program written by one of the investigators (MM) that used standard statistical formulae (Winer et al. 1991). To identify brain voxels where the pattern-flash stimulus caused changes in rCBF in the absence of drug, a 1-factor ANOVA with flash-frequency as the repeated measure was performed on 19 subjects in the NO-DRUG condition. Compared to NO-DRUG, the PHYSO effect on rCBF was analyzed in 19 subjects, across five pattern-flash conditions, using a 2-factor (PHYSO, pattern-flash) 5level repeated measures $(0,1,4,7,14 \mathrm{~Hz})$ ANOVA. All three drug conditions were analyzed in 10 subjects using a 2-factor repeated measures ANOVA consisting of a 3-level drug-condition NO DRUG, PHYSO, and $\mathrm{PHYSO}+\mathrm{SCOP})$, and a 3-level repeated measures pattern-flash factor $(0,7$, and $14 \mathrm{~Hz})$. Simple effects were analyzed using Newman-Keuls post hoc tests.

The F scores from the ANOVAs on each brain voxel were converted to Z score maps (Paulson 1942; Federighi 1959). Z scores for significant pattern-flash or drug main effects were thresholded at $Z>2.33$. Clusters of statistically significant voxels whose extent exceeded a $p<.05$ 2-tailed probability, corrected for multiple comparisons, were identified using the NIH Functional Imaging Data Analysis Platform (FIDAP, written by Dr. J Maisog) based on the algorithms used in Statistical Parametric Mapping (Friston et al. 1994). In Table 1, rCBF during NO-DRUG, PHYSO, and PHYSO+SCOP are presented for representative local maxima from regions identified by the various ANOVA main effects. (A local maximum is that voxel within the statistically significant region that has the highest $Z$ score within a radius of 12 voxels along the $x, y$ and $z$ axes.) Significant post hoc simple effects according to Newman-Keuls test are indicated. A pictorial overview illustrating the anatomic extent of these results is presented in Figure 1. The multiple-comparison corrected $\mathrm{Z}$ maps from the different ANOVAs were superimposed on a structural MRI scan that had been placed into Talairach space. Voxels with a significant main effect were color coded to demonstrate informative simple effects. Simple effects for the pictorial display (Figure 1) were determined using post-hoc $\mathrm{t}$ tests, not Newman-Keuls tests. 
Table 1. Regional Blood Flow During NO-DRUG, PHYSO, and PHYSO+SCOP in Brain Regions with Significant Response to Pattern Flash Stimulus. Values Are Means \pm S.E. at Local Maxima

\begin{tabular}{|c|c|c|c|c|c|c|}
\hline \multirow[b]{2}{*}{ Brain Region } & \multirow[b]{2}{*}{ Coords } & \multirow{2}{*}{$\begin{array}{l}\text { Effect of Pattern-Flash } \\
\text { (during NO-DRUG) }\end{array}$} & \multicolumn{4}{|c|}{ Scaled Local Blood Flow (ml/100g/min) } \\
\hline & & & Group Size & NO-DRUG & PHYSO & PHYSO +SCOP \\
\hline Striate Cortex & $-6-940$ & \multirow{3}{*}{$p<.001$} & $\mathrm{n}=10$ & $55.1 \pm 1.1$ & $55.1 \pm 1.2$ & \multirow[t]{2}{*}{$52.7 \pm 1.5^{\mathrm{b}, \mathrm{c}}$} \\
\hline (BA 17) & $-6-900$ & & $\mathrm{n}=19$ & $55.0 \pm 0.6$ & $55.1 \pm 0.7$ & \\
\hline Occipital Cortex & $26-8816$ & & $\mathrm{n}=10$ & $40.8 \pm 1.0$ & $39.5 \pm 0.8^{\mathrm{b}}$ & \multirow[t]{2}{*}{$41.6 \pm 0.9^{\mathrm{b}, \mathrm{c}}$} \\
\hline (BA 19) & 39-90 16 & \multirow[t]{2}{*}{$p<.001$} & $\mathrm{n}=19$ & $43.1 \pm 0.4$ & $41.7 \pm 0.4^{\mathrm{a}}$ & \\
\hline Inferior Parietal & $54-4824$ & & $\mathrm{n}=10$ & $48.4 \pm 0.9$ & $47.3 \pm 0.6^{\mathrm{b}}$ & \multirow[t]{2}{*}{$46.0 \pm 0.9^{\mathrm{b}, \mathrm{c}}$} \\
\hline$(\mathrm{BA} 39 / 40)$ & $54-3824$ & \multirow[t]{2}{*}{$p<.01$} & $\mathrm{n}=19$ & $48.8 \pm 0.3$ & $47.8 \pm 0.4^{\mathrm{a}}$ & \\
\hline \multirow{2}{*}{ Thalamus } & $6-224$ & & $\mathrm{n}=10$ & $46.2 \pm 0.6$ & $48.5 \pm 0.9^{\mathrm{b}}$ & \multirow[t]{2}{*}{$47.3 \pm 1.0$} \\
\hline & $-18-180$ & $p<.01$ & $\mathrm{n}=19$ & $44.6 \pm 0.2$ & $46.6 \pm 0.3^{a}$ & \\
\hline
\end{tabular}

${ }^{a}$ Significant difference from NO-DRUG, $p<.01$. (According to 2-factor ANOVA drug main effect.)

bSignificant difference from NO-DRUG, $p<.05$. (According to 2-factor ANOVA and Newman-Keuls test.)

'Significant antagonism of physostigmine effect by scopolamine, $p<.05$. (According to 2 -factor ANOVA and Newman-Keuls test.)

\section{RESULTS}

\section{Neuropsychological Results}

Mean scores for the Buschke selective reminding task acquired immediately after the PHYSO+SCOP scan session were $40.5 \% \pm 13.4$ lower than values acquired at baseline just prior to scopolamine administration $($ mean $\pm \mathrm{SD}, \mathrm{t}(9)=10.3, p<.001)$.

\section{Regional Cerebral Blood Flow Results}

Absolute global CBF ("raw" values of blood flow assessed prior to normalization or other data manipulation procedures) was no different between groups across drug conditions ( $p=.6$, data not shown), illustrating that drug administration did not have a direct vascular effect of sufficient magnitude to alter global CBF.

Table 1 shows rCBF values during NO-DRUG, $\mathrm{PHYSO}$, and PHYSO+SCOP at local maxima of brain regions with a significant main effect of drug. We checked that each local maximum also had a significant rCBF response to the pattern-flash stimulus in the absence of drug, supporting the concept that $\mathrm{ACh}$ is a neuromodulator of target neural activity (see Introduction). Physostigmine administration (PHYSO) augments acetylcholine action present during the NO-DRUG (endogenous) condition. This could be muscarinic action, nicotinic action or both depending on receptor concentrations. PHYSO+ SCOP antagonizes the action of PHYSO by blocking muscarinic but not nicotinic receptors. Antagonism of muscarinic action by scopolamine occurs with approximately equal effect across M1 and M2 receptors (Watson et al. 1984); the more numerous of the muscarinic receptors.

In striate cortex (BA 17), physostigmine administration did not change rCBF compared to NO-DRUG, while scopolamine antagonism (PHYSO+SCOP) significantly reduced rCBF compared to both PHYSO and NO-DRUG conditions (Table 1). A parsimonious expla- nation for the observation that scopolamine antagonism reduced rCBF compared to NO-DRUG might be an endogenous muscarinic effect increasing rCBF. However, the failure of PHYSO to augment this endogenous effect suggests that it was already saturated in the NODRUG condition. In middle occipital gyrus (BA 19) physostigmine activation significantly reduced $\mathrm{rCBF}$, and muscarinic antagonism of this physostigmine action significantly increased rCBF above both PHYSO and NO-DRUG levels (Table 1). This pattern of rCBF responses is consistent with an endogenous muscarinic effect decreasing rCBF. In inferior parietal lobule (39/ 40) physostigmine significantly reduced rCBF compared to NO-DRUG (Table 1). Scopolamine antagonism failed to reverse this effect suggesting that physostigmine augmented an endogenous nicotinic effect reducing rCBF. Further, scopolamine antagonism reduced rCBF levels compared to PHYSO, suggesting that in addition to the endogenous nicotinic effect reducing $\mathrm{rCBF}$, there was a smaller endogenous muscarinic effect increasing $\mathrm{rCBF}$ in inferior parietal lobule. In thalamus, physostigmine activation significantly increased $\mathrm{rCBF}$, while scopolamine antagonism reduced $\mathrm{rCBF}$ to a value between NO-DRUG and PHYSO that was not significantly different from either (Table 1). Endogenous nicotinic activity increasing $\mathrm{rCBF}$ is compatible with this pattern of rCBF responses. Figure 1 is a pictorial summary of these results through three axial slices.

\section{Drug Effects and Side-effects}

Both physostigmine and scopolamine drug regimens were well tolerated. During PHYSO, there was an average increase in pulse of five beats per minute and an average increase in blood pressure of $5-10 \mathrm{~mm} \mathrm{Hg}$, most likely due to glycopyrrolate. Two subjects reported mild nausea while being returned to the ward after the tenth scan was completed. The nausea resolved and vital signs were back to baseline within 20-30 min after stopping 

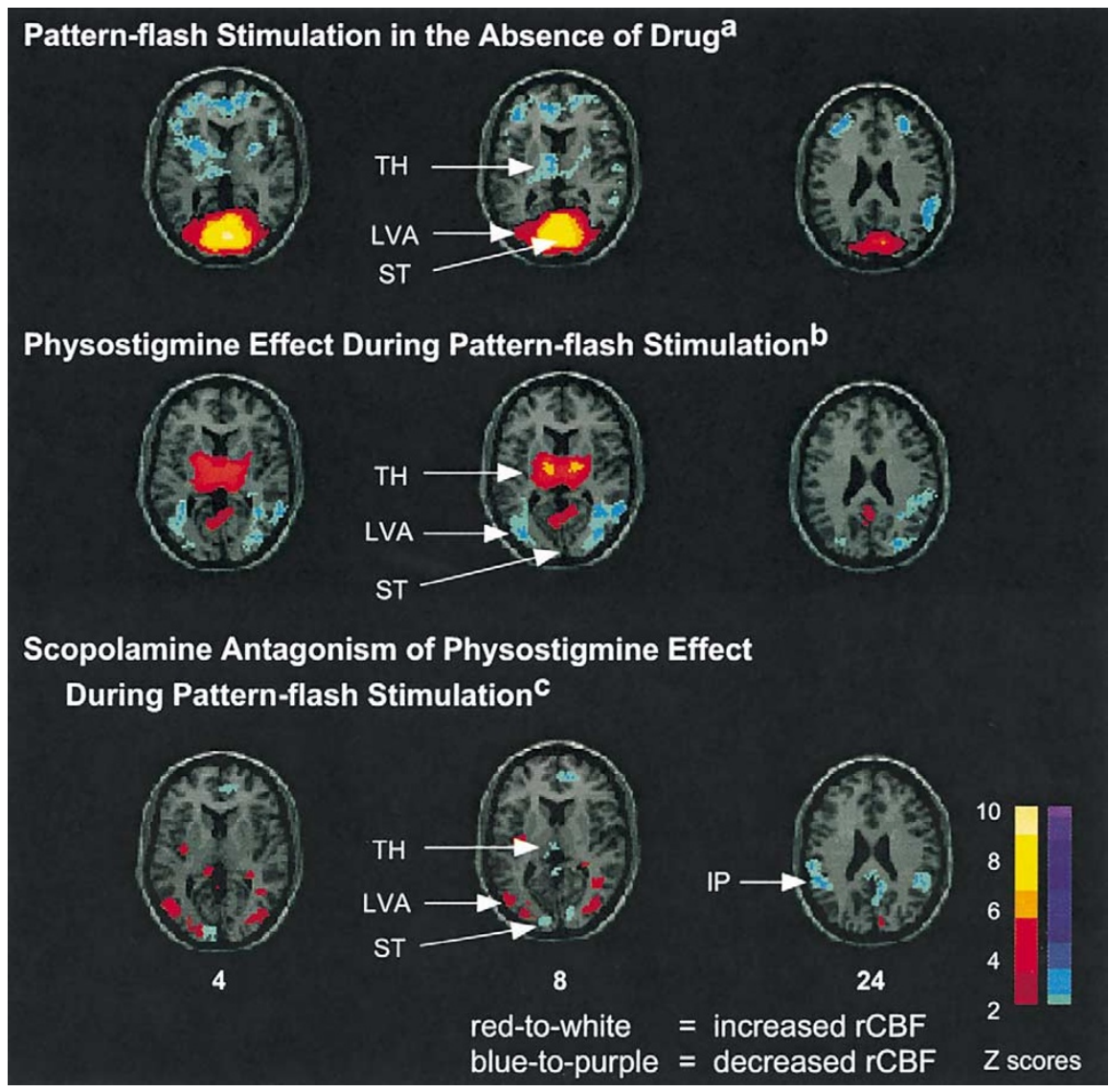

Figure 1. Drug Modulation of rCBF Response to Pattern-flash Stimulus. Z maps of various main effects have been color coded to illustrate simple effects. $Z$ scores represent the size of the main effect not the various simple effects. ${ }^{\text {a }}$ Main effect of pattern flash during NO-DRUG $(\mathrm{n}=19)$ color-coded to show those voxels with increasing (red-scale) and decreasing (bluescale) rCBF as flash-frequency increased. ${ }^{\mathrm{b}}$ Main effect of PHYSO $(\mathrm{n}=19)$ color-coded to show those voxels where rCBF during PHYSO was greater (red-scale) and less than (blue-scale) NO-DRUG. ' Main effect of drug across NO-DRUG, PHYSO, and PHYSO+SCOP $(n=10)$ color-coded to show those voxels where PHYSO+SCOP was greater (red-scale) and less than (blue-scale) PHYSO or NO-DRUG. Axial slices 4, 8 and $24 \mathrm{~mm}$ above the Anterior-Posterior commissure line. rCBF, regional cerebral blood flow. PHYSO, physostigmine plus glycopyrrolate administration. PHYSO+SCOP, scopolamine plus physostigmine administration. The effects of drug (bottom two rows) occurred primarily in regions activated by the pattern-flash stimulus (top row). In striate cortex (ST) physostigmine activation had no effect on rCBF compared to NO-DRUG (middle row), while scopolamine antagonism reduced rCBF to levels significantly below PHYSO and NO-DRUG (bottom row). In lateral visual association areas (LVA) physostigmine activation significantly reduced rCBF compared to NO-DRUG (middle row), while scopolamine antagonism of physostigmine effect increased rCBF significantly compared to PHYSO and NODRUG (bottom row). In inferior parietal cortex (IP) physostigmine activation significantly reduced rCBF compared to NODRUG (middle row), and scopolamine antagonism significantly reduced rCBF further (bottom row). In thalamus (TH) physostigmine activation significantly increased rCBF (middle row), but muscarinic antagonism failed to alter rCBF (bottom row). Scopolamine reduced rCBF to a level below PHYSO and above NO-DRUG but not significantly different from either.

the physostigmine infusion. During PHYSO $+\mathrm{SCOP}$ there was an immediate increase in pulse by 15 to 30 beats per minute, and an increase in blood pressure by 10 to $20 \mathrm{~mm} \mathrm{Hg}$. The pulse returned slowly to baseline over about 1 to 2 hours while blood pressure normalized over 10 to 15 minutes. The study was aborted in the dose-finding stage in two subjects; a male with unrecognized prostatic hypertrophy developed acute reversible urinary retention after scopolamine administration, and a female developed nausea and vomiting after a few minutes of physostigmine maintenance infusion.

\section{DISCUSSION}

These results support the notion that as in other vertebrates, ACh is an important modulator of visual processing in humans. As might be expected from the topographic specificity of cholinergic projections, and the differential distribution of cholinergic receptors, our results suggest that endogenous ACh has differing effects on function in brain regions activated by a pattern flash stimulus. Using a 3-level drug design (NO-DRUG, PHYSO, PHYSO+SCOP) and PET allowed us to de- 
velop evidence to determine whether cholinergicallyinduced $\mathrm{rCBF}$ changes in a particular brain region were composed of relative muscarinic activity, nicotinic activity, or both. Specifically, we found that ACh modulation in striate cortex (BA 17) and lateral visual association cortex (BA 18, 19) appeared to have a significant muscarinic action, while ACh modulation in inferior parietal lobule and thalamus appeared to have a significant nicotinic action. Further, both muscarinic and nicotinic activity had the effect of increasing $\mathrm{rCBF}$ in one region while decreasing it in another.

Using arterial lines to calculate absolute levels of blood flow, we have previously described rCBF responses to the pattern-flash stimulus from striate through frontal cortices in healthy elderly subjects in the absence of drug administration (Mentis et al. 1997). In this study we have confirmed our previous findings that during NO DRUG, the largest rCBF response to the pattern-flash stimulus ( $35 \%$ of global mean) occurred in striate cortex with smaller responses in bilateral visual association areas (increased $\mathrm{rCBF}$ ), inferior parietal lobule (decreased rCBF), thalamus (decreased $\mathrm{rCBF}$ ) and frontal lobes (decreased rCBF).

\section{Regions with a Significant Muscarinic Effect: Striate Cortex (BA 17) and Lateral Visual Association Areas (BA 18, 19)}

Blood flow change observed during PET represent net change primarily in synaptic activity (review: Jeuptner and Weiller 1995). Clearly, synaptic activity can be increased in a given brain region by facilitating activity in a distal neuron that projects into the region, or facilitating activity in an interneuron that projects to other layers within the region. Either facilitatory or inhibitory postsynaptic effects of these two neurons will increase synaptic activity and $\mathrm{rCBF}$ in the region. Synaptic activity within a region can be decreased by inhibiting or reducing the firing rate of a distal neuron that projects into the region.

In single cell experiments in cats using iontophoretic physostigmine, scopolamine, and a drug to inhibit GABA function, a prominent muscarinic effect was found in $80 \%$ of neurons in striate cortex during optic nerve stimulation. Direct muscarinic facilitation increased the firing rates in $70 \%$ of these neurons, and muscarinic facilitation of local GABA interneurons decreased the firing rate in $30 \%$. Extrapolating to our study, both the direct facilitatory effect on cholinoceptive neurons and the augmentation of GABA interneurons would increase synaptic activity in striate cortex. This is consistent with our finding that endogenous $\mathrm{rCBF}$ in striate cortex was increased by muscarinic action (Table 1, Figure 1). Muscarinic antagonism by scopolamine (PHYSO $+\mathrm{SCOP}$ ) reduced $\mathrm{rCBF}$ to a level significantly lower than that observed during NO-DRUG suggesting an endogenous muscarinic effect increasing $\mathrm{rCBF}$. That physostigmine augmentation
(PHYSO) failed to change rCBF levels compared to NODRUG, suggests the endogenous muscarinic effect had saturated the muscarinic receptors.

Muscarinic receptors, particularly the M1 receptor, are abundant on cholinoceptive neurons in the outer layers of striate and extrastriate visual cortices (BA17, 18, 19) (Cymerman et al. 1987; Mash et al. 1988; Schliebs et al. 1994). Pyramidal neurons from these layers project proximally and distally along the visual networks. Thus, the cholinergic system is well positioned to modulate feedforward and feed-back visual processing. Based on these considerations and the differential effect of muscarinic activity within striate cortex in the single cell cat experiments, Sato (Sato et al. 1987b) suggested " ... the cholinergic innervation to cortical neurons may play a role in improvement of the $\mathrm{S} / \mathrm{N}$ [signal-to-noise ratio] of information processing in the striate cortex and in facilitation of sending processed informations to other visual centers". The pattern flash stimulus is composed of simple visual forms that, consistent with hierarchical visual processing, result in greatest activation in striate cortex where simple forms are processed and progressively smaller activation in distal regions that respond maximally to complex visual attributes (Mentis et al. 1997). Thus, in keeping with the notion that $\mathrm{ACh}$ increases signal-to-noise, ACh should increase inhibition of those neurons in striate cortex that project to association areas responsible for processing visual attributes more complex than those present in the pattern-flash stimulus. This action of ACh would result in a net increase in synaptic activity in the striate cortex and a net decrease in synaptic activity in distal visual association areas. This explanation is consistent with our finding that endogenous muscarinic action increased rCBF in striate cortex and decreased rCBF in more distal visual association areas. In middle occipital gyrus (BA 19) physostigmine activation significantly reduced $\mathrm{rCBF}$, while muscarinic antagonism of this action increased $\mathrm{rCBF}$ to a level significantly higher than that during NO-DRUG (Table 1, Figure 1).

In summary, based on known function within these regions, the muscarinic actions in striate cortex and lateral visual association regions may be primarily concerned with modulating various attributes (form, position, motion) of the pattern-flash stimulus. The hypotheses that visual processing is hierarchical, and that muscarinic modulation reduces the signal-to-noise ratio are consistent with the finding that endogenous muscarinic action increased rCBF in striate cortex and reduced it in lateral visual association regions.

\section{Regions with a Significant Nicotinic Effect: Thalamus and Inferior Parietal Lobules (BA 39/40)}

Anatomical connections between thalamus and visual brain regions demonstrate that the thalamus is involved in visual processing on several levels. Visual 
pathways relay in the lateral geniculate nucleus before reaching the cortex (Mason and Kandel 1991) and then connect reciprocally with the pulvinar after passing to cortical extrastriate regions (Kelly 1991). Lateral geniculate and pulvinar nuclei are modulated by cholinergic neurons from $\mathrm{Ch} 5$, and both have high concentrations of presynaptic nicotinic receptors (Perry et al. 1989; Spurden et al. 1997; Paterson and Nordberg 2000). Consistent with these anatomical features, we found that physostigmine activation significantly increased $\mathrm{rCBF}$ in thalamus, while scopolamine antagonism failed to reduce it (Table 1, Figure 1). This suggests physostigmine augmented an endogenous nicotinic action increasing $\mathrm{rCBF}$ in the thalamus.

Functionally, nicotinic action is strongly associated with arousal and attention (review: Wecker and $\mathrm{Yu}$ 1995). Posner and Dehaene (Posner and Dehaene 1994) have proposed a posterior attention circuit that includes thalamo-parietal interconnections. We found that scopolamine antagonism failed to reverse the effect of physostigmine in inferior parietal lobule (39/40) (Table 1, Figure 1). This suggests the $\mathrm{rCBF}$ reduction during PHYSO compared to NO-DRUG was an augmentation of endogenous nicotinic action decreasing rCBF. As projections from $\mathrm{Ch} 5$ are part of the reticular activating system and have connections with lateral geniculate nucleus and pulvinar, these projections likely play an important role in arousal and selective visual attention. Further, as parieto-pulvinar tracts are part of the visual pathways and $\mathrm{Ch} 5$ projections are rich in presynaptic nicotinic receptors, our finding of a nicotinic action modulating thalamic and inferior parietal cortex suggests that nicotinic action may be important in arousal and selective attention to the pattern-flash stimulus.

In light of the neuromodulatory rather than primary neurotransmitter functions of ACh (see Introduction), we suggest that $\mathrm{ACh}$ modulation of brain function in humans might be best studied during task performance in the specific regions activated by the task. In this vein, ACh modulation of brain function at "rest" should be interpreted with caution. Consistent with our findings, several studies have reported scopolamine induced $\mathrm{rCBF}$ increases in lateral visual association areas, but during tasks that are primarily non-visual (Grasby et al. 1995; Bahro et al. 1999). These changes may, nonetheless, reflect modulation of visual perception or visual imagery that occurred while the tasks were performed. Although rCBF reduction by scopolamine in thalamus was only a trend in our study, significant scopolamineinduced rCBF reduction during various tasks has been reported by others (Cohen et al. 1994; Grasby et al. 1995; Bahro et al. 1999). Cohen and colleagues (Cohen et al. 1994) described a scopolamine-induced reduction in thalamic glucose metabolism during an auditory continuous performance task that was interpreted as evidence for muscarinic-dependent increased thalamic function during attention. These studies and ours deal with acute changes in rCBF during scopolamine administration. Rosier and colleagues evaluated chronic rCBF changes during a shape recognition test three days after scopolamine-impaired learning. As in our study, they found $\mathrm{rCBF}$ changes in fusiform gyrus, parietal lobe, and thalamus, but their rCBF changes were in the opposite direction to ours. Their interpretation that these chronic rCBF values represent functional compensation in the opposite direction to acute changes make their findings consistent with ours.

Methodological Issues. We have previously demonstrated (Mentis et al. 1997) good test-retest reliability when the pattern-flash stimulus was repeated in the same scan session in the absence of drug. Therefore, in this study, we are able to attribute any change in $\mathrm{rCBF}$ during drug to a drug-effect rather than to placebo, priming, attenuation, or facilitation effects. However, out of concern for patient safety and comfort we presented the drugs in a fixed order (see METHODS). Although we have no compelling theoretical reason to suspect a drug-order effect in this study, whether our results are confounded by such an effect remains to be determined.

As muscarinic and nicotinic receptors can cause direct cerebral vasodilation in multiple brain regions (Arneric 1989; Biesold et al. 1989; Sato and Sato 1995), a potential confound exists when using rCBF change as an index of neural function. We believe that the results presented in this study reflect synaptic activity and not direct vascular effects for several reasons. We placed arterial lines to calculate absolute blood flow values and failed to demonstrate an effect of drug on global mean blood flow. The same drug had different effects on blood flow in different brain regions. Drug-induced changes in blood flow in regions outside those activated by the pattern-flash stimulus were not significant. Taken together these results suggest the absence of a direct, consistent vascular effect unrelated to stimulus.

Conclusion. Our results suggest that acetylcholine is a significant modulator of visual processing in humans. Our findings that muscarinic and nicotinic contributions to ACh modulation of the pattern-flash stimulus differed in different brain regions, and that both muscarinic and nicotinic action could increase synaptic activity in one brain region while decreasing it in another are consistent with the topographic anatomy of cholinergic projections and the differential distribution of cholinergic receptors. The hypotheses that visual processing is hierarchical, and that muscarinic modulation improves the signal-to-noise ratio may explain our finding that in our simple task, endogenous muscarinic action increased $\mathrm{rCBF}$ in striate cortex and decreased it in extrastriate regions. The pattern of $\mathrm{rCBF}$ responses across the drug conditions was consistent with a pre- 
dominantly muscarinic action in striate cortex and extrastriate regions (BA 17, 18, 19) and a predominantly nicotinic action in thalamic nuclei and inferior parietal lobule (BA 39/40). Reconciling known functional anatomy with these regional observations, we speculated that muscarinic activity might be important in modulating pattern-flash attribute processing. By contrast, nicotinic activity might be important in modulating arousal and selective visual attention.

\section{REFERENCES}

Arneric SP (1989): Basal forebrain neurons modulate cortical cerebral blood flow: increases by nicotinic cholinergic mechanism. J Cereb Blood Flow Metab 9:S502

Bahro M, Molchan SE, Sunderland T, Herscovitch P, Schreurs BG (1999): The effects of scopolamine on changes in regional cerebral blood flow during classical conditioning of the human eyeblink response. Neuropsychobiology 39:187-195

Barefoot HC, Baker HF, Ridley RM (2000): Synergistic effects of unilateral immunolesions of the cholinergic projections from the basal forebrain and contralateral ablations of the inferotemporal cortex and hippocampus in monkeys. Neuroscience 98:243-251

Biesold D, Inanami O, Sato A, Sato Y (1989): Stimulation of the nucleus basalis of Meynert increases cerebral cortical blood flow in rats. Neurosci Lett 98:39-44

Buschke H, Fuld PA (1974): Evaluating storage, retention, and retrieval in disordered memory and learning. Neurology 24:1019-1025

Carson RE, Berg GW, Finn RD, Patlak CS, Daube-Witherspoon ME, Stein SD, Simpson NR, Green MV, Larson SM (1987): Tomographic measurement of LCBF with high-resolution PET and H215O: comparison of methods. J Cereb Blood Flow Metab 7

Clarke PB (1993): Nicotinic receptors in mammalian brain: localization and relation to cholinergic innervation. Prog Brain Res 98:77-83

Cohen RM, Gross M, Semple WE, Nordahl TE, Sunderland $\mathrm{T}$ (1994): The metabolic brain pattern of young subjects given scopolamine. Exp Brain Res 100:133-143.

Court J, Perry E (1995): Distribution of nicotinic receptors in the CNS. In Stone TW (ed), CNS Neurotransmitters and Neuromodulators: Acetylcholine. London, CRC Press, pp 85-104

Cymerman U, Palacios JM, Cortes R, Skangiel-Kramska J (1987): Autoradiographic localization of muscarinic cholinergic receptors in visual areas of cat brain: variations in sensitivity of $\mathrm{N}-[3 \mathrm{H}]$ methylscopolamine binding sites to carbachol and pirenzepine. Neurosci Lett 81:13-18

Desimone R, Ungerleider LG (1989): Neural mechanisms of visual processing in monkeys. In Goodglass H, Damasio AR (eds), Handbook of Neuropsychology. Amsterdam, Elsevier, pp 267-300

Federighi ET (1959): Extended tables of the percentage points of Student's t-distribution. J Am Stat Assoc 54:683-688
Felleman DJ, Van Essen DC (1991): Distributed hierarchical processing in the primate cerebral cortex. Cereb Cortex $1: 1-47$

Fibiger HC, Vincent SR (1987): Anatomy of central cholinergic neurons. New York, Raven Press

Friston KJ, Worsley KJ, Frackowiak RSR, Mazziotta JC, Evans AC (1994): Assessing the significance of focal activations using their spatial extent. Human Brain Mapping 1:210-220

Geula G, Mesulam MM (1994): Cholinergic systems and related neuropathological predilection patterns in Alzheimer Disease. In Terry RD, Katzman R, Bick KL (eds), Alzheimer Disease. New York, Raven, pp 263-291

Grady CL, Haxby JV, Horwitz B, Schapiro MB, Ungerleider LG, Mishkin M, Carson RE, Herscovitch P, Rapoport SI (1990): Changes in regional cerebral blood flow (rCBF) demonstrate separate visual pathways for object discrimination and spatial location. J Clin Exp Neuropsychol 12:93

Grasby PM, Frith CD, Paulesu E, Friston KJ, Frackowiak RS, Dolan RJ (1995): The effect of the muscarinic antagonist scopolamine on regional cerebral blood flow during performance of a memory task. Exp Brain Res 104:337-348

Holden JE, Gatley SJ, Hichwa RD, Ip WR, Shaughnessy WJ, Nickles RJ, Polycn RE (1981): Cerebral blood flow using PET measurements of fluoromethane kinetics. J Nucl Med 22:1084-1088

Jeuptner M, Weiller C (1995): Review: Does measurement of regional cerebral blood flow reflect synaptic activity? Implications for PET and fMRI. NeuroImage 2:148-156

Kelly JP (1991): The neural basis of perception and movement. In Kandel ER, Schwartz JH, Jessel TM (eds), Principles of neural science, Third Edition. New York, Elsevier, pp 283-295

Kubo T, Fukuda K, Mikami A, Maeda A, Takahashi H, Mishina M, Haga T, Haga K, Ichiyama A, Kangawa K, Kojima M, Matsuo H, Hirose T, Numa S (1986): Cloning, sequencing and expression of complementary DNA encoding the muscarinic acetylcholine receptor. Nature 323:411-416

Livingstone MS, Hubel DH (1987): Psychophysical evidence for separate channels for the perception of form, color, movement and depth. J Neurosci 7:3416-3468

London ED, Dam M, Fanelli RJ (1988): Nicotine enhances cerebral glucose utilization in central components of the rat visual system. Brain Res Bull 20:381-385

Lukas RJ, Changeux JP, Le Novere N, Albuquerque EX, Balfour DJ, Berg DK, Bertrand D, Chiappinelli VA, Clarke PB, Collins AC, Dani JA, Grady SR, Kellar KJ, Lindstrom JM, Marks MJ, Quik M, Taylor PW, Wonnacott S (1999): International Union of Pharmacology. XX. Current status of the nomenclature for nicotinic acetylcholine receptors and their subunits. Pharmacol Rev 51:397-401

Martinez-Murillo R, Rodrigo J (1995): The localization of cholinergic neurons and markers in the CNS. In Stone TW (ed), CNS neurotransmitters and neuromodulators: Acetylcholine. London, CRC Press, 1-36

Mash DC, White WF, Mesulam MM (1988): Distribution of muscarinic receptor subtypes within architectonic subregions of the primate cerebral cortex. J Comp Neurol 278:265-274 
Mason C, Kandel ER, (1991): Central visual pathways. In Kandel ER, Schwartz JH, Jessel TM (eds), Principles of neural science, Third Edition. New York, Elsevier, pp 421-439

McCormick D, Prince DA (1985): Two types of muscarinic response to acetylcholine in mammalian cortical neurons. Proc Natl Acad Sci 82:6344-6348

Mentis MJ, Alexander GE, Grady CL, Horwitz B (1996a). On analyzing and interpreting PET activation data in the presence of significant and biologically meaningful group global mean differences. Human Brain Mapping, 2nd International Conference on Functional Mapping of the Human Brain. Boston, Academic Press

Mentis MJ, Alexander GE, Grady CL, Horwitz B, Krasuski J, Pietrini P, Strassburger T, Hampel H, Schapiro MB, Rapoport SI (1997): Frequency variation of a patternflash visual stimulus during PET differentially activates brain from striate through frontal cortex. Neuroimage 5:116-128

Mentis MJ, Alexander GE, Krasuski J, Pietrini P, Furey ML, Schapiro MB, Rapoport SI (1998): Increasing required neural response to expose abnormal brain function in mild versus moderate or severe Alzheimer's disease: PET study using parametric visual stimulation. Am J Psychiatry 155:785-794

Mentis MJ, Horwitz B, Grady CL, Alexander GE, VanMeter JW, Maisog JM, Pietrini P, Schapiro MB, Rapoport SI (1996b): Visual cortical dysfunction in Alzheimer's disease evaluated with a temporally graded "stress test" during PET. Am J Psychiatry 153:32-40

Muller CM, Singer W (1989): Acetylcholine-induced inhibition in the cat visual cortex is mediated by a GABAergic mechanism. Brain Research 487:335-342

Paterson D, Nordberg A (2000): Neuronal nicotinic receptors in the human brain. Prog Neurobiol 61:75-111

Paulson E (1942): An approximate normalization of the Analysis of Variance distribution. Ann Math Statist

Perry EK, Smith CJ, Perry RH, Whitford C, Johnson M, Birdsall NJ (1989): Regional distribution of muscarinic and nicotinic cholinergic receptor binding activities in the human brain. Journal of Chemical Neuroanatomy 2:189-199

Posner MI, Dehaene S (1994): Attentional networks. Trends Neurosci 17:75-79

Robner S, Schliebs R (1995): Distribution of Muscarinic Acetylcholine Receptors in the CNS. In Stone TW (ed), CNS neurotransmitters and Neuromodulators: Acetylcholine. London, CRC Press, 67-82
Rosier A-M, Cornette L, Dupont P, Bormans G, Mortelmans L, Orban GA (1999): Regional brain activity during shape recognition impaired by a scopolamine channenge to encoding. Eur J Neurosci 11:3701-3714

Sato A, Sato Y (1995): Cholinergic neural regulation of regional cerebral blood flow. Alzheimer Disease and associated disorders 9:28-38

Sato H, Hagihara K, Tsumoto T (1987a): Effects of cholinergic depletion on neuron activities in the cat visual cortex. Journal of Neurophysiology 58:781-793

Sato H, Hata Y, Masui H, Tsumoto T (1987b): A functional role of cholinergic innervation to neurons in the cat visual cortex. Journal of Neurophysiology 58:765-780

Schliebs R, Rossner S, Kumar A, Bigl V (1994): Muscarinic acetylcholine receptor subtypes in rat visual cortex-a comparative study using quantitative receptor autoradiography and in situ hybridization. Indian J Exp Biol 32:25-30

Sillito AM, Kemp JA (1983): Cholinergic modulation of the functional organization of the cat visual cortex. Brain Research 289:143-155

Sillito AM, Salt TE, Kemp JA (1985): Modulatory and inhibitory processes in the visual cortex. Vision Res 25:375-381

Spurden DP, Court JA, Lloyd S, Oakley A, Perry R, Pearson C, Pullen RG, Perry EK (1997): Nicotinic receptor distribution in the human thalamus: autoradiographical localization of [3H]nicotine and [125I] alpha-bungarotoxin binding. J Chem Neuroanat 13:105-113

Talairach J, Tournoux P (1988): Co-planar stereotaxic atlas of the human brain. New York, Thieme Medical Publishers, Inc.

Watson M, Vickrow TW, Roeske WR, Yamamura HI (1984): Subclassification of muscarinic receptors based upon the selective antagonist pirenzepine. Trends Pharmacol Sci Febr. Suppl. 9

Wecker L, Yu ZJ (1995): Function of nicotinic receptors in the CNS. In Stone TW (ed), CNS neurotransmitters and neuromodulators: Acetylcholine. London, CRC Press, pp 105-114

Winer BJ, Brown DR, Michels KM (1991): Statistical Principles in Experimental Design. New York, McGraw-Hill

Woods RP, Grafton ST, Watson JD, Sicotte NL, Mazziotta JC (1998): Automated image registration: II. Intersubject validation of linear and nonlinear models. J Comput Assist Tomogr 22:153-165 